\title{
Cultural Value Diversity: Influence towards Multicultural Teamwork Performance among Restaurant Employees
}

\author{
Ab-Latif, Z.1 ${ }^{*}$, Asilah, A. M. ${ }^{2}$, Zalina, I. ${ }^{2}$, Fazhana, I. ${ }^{2}$, Shaibatul ' Islamiah, C. M. ${ }^{2}$. \\ ${ }^{1}$ Family and Consumer Science, Faculty of Technical and Vocational, Universiti Pendidikan Sultan \\ Idris, 35900 Tanjong Malim, Perak, Malaysia. \\ 2 Department of Agricultural Science, Universiti Pendidikan Sultan Idris, Malaysia. \\ *Corresponding author, e-mail: zahidah@ftv.upsi.edu.my
}

\begin{abstract}
Malaysia currently has a diverse workforce, relying on foreign workers in the hospitality industry. This study tested a conceptual model to investigate the role of specific cultural diversity value in influencing multicultural teamwork performance. A self-administered questionnaire was conducted in casual ethnic restaurants in Malaysia. The findings revealed that the three diversity dimensions of collectivism, determinism, and orientation each had distinctive effects on productivity and/or cooperation. This study offers new insights on cultural value diversity and multicultural teamwork performance at a dimensional level thus provides rigid answer for the argument from previous scholars. In addition, by providing the current phenomena in workforce industry, this study helps the restaurant managers to prepare with strategic management on handling diversity among multicultural team.
\end{abstract}

Keywords: Cultural value diversity, collectivism, determinism, orientation, teamwork performance, productivity, cooperation.

How to Cite: Ab-Latif, Z. et. al. (2020). Cultural Value Diversity: Influence towards Multicultural Teamwork Performance among Restaurant Employees. Journal of Vocational Education Studies, 3(2), 13-24. DOI: https://doi.org/10.12928/ joves.v3i2.2933.

\section{INTRODUCTION}

The impact of cultural diversity on team success have been given great importance as there are growing numbers of companies using teams as their basic framework to improve thecompetitive advantage (Barak, 2013; Dienes \& Velte, 2016). Diversity and cultural differences are important elements in determining an organization's culture and performance. Diversity, defined as distinctly different group affiliations of cultural significance in one social system (Eze, Okonkwo, Oluchi, \& Igwebuike, 2019), is one of the most pressing issues dealing with the future workforce (Testa, 2007). The cultural differences among employees are expressed in the way a team works in unity (i.e. collectivism diversity, determinism diversity, and doing orientation). An employee's ethnic culture may affect his or her perception of work environment and performance (Hofstede, 1991).

Recent studies have addressed the adverse effects of workforce diversity on team performance. Some studies indicate that cultural diversity has resulted in improved decision-making, increased creativity, efficient marketing, and a possible competitive advantage for organisations (Alesina \& LaFerrara, 2005; Timmermans, Ostergaard, \& Kristinsson, 2011). Kahane, Longley, and Simmons (2013) suggest that it may be useful to widen the workforce to foreign workers. In addition, diversity in work groups could result in better work solutions, or in declining unity (Webber \& Donahue, 2001).

On the other hand, some claim that differences in cultures and languages have adversely affected the success of teamwork within an organisation because workers share a lack of expertise and shared concepts, weak communication, and less cooperation (Dahlin, 2005; Lazear, 1999). The greater the cultural context gaps, more misunderstandings and

Received October 09, 2020; Revised November 28, 2020; Accepted November 28, 2020 
conflict occur at the workplace (Ab-Latif, 2019). A recent research indicates that benefits from diversity could be greatest when the workforce has a higher degree of homogeneity (i.e. race, language) (Kahane, Longley, \& Simmons, 2013).

As shown above, previous studies have provided some insights into the broader picture of workforce diversity and cultural differences. However, the impact of diversity on work outcomes has been still debated (Pelled, Eisenhardt, \& Xin, 1999) while there is no consensus on diversity's impact towards teamwork performance. Hence, more extensive research is needed to examine the impact of cultural value diversity on team outcomes.

Moreover, while researchers have agreed that both cultural value diversity and teamwork performance are significantly related (Kirkman \& Shapiro, 2005; Tröster, Mehra, \& Knippenberg, 2014), little research has further investigated the underlying relationships between dimensions of cultural value diversity (i.e. collectivism, determinism, doing orientation) and work performance (i.e., productivity, cooperation). Accordingly, research is needed to further examine the specific relationships among subdimensions of each construct.

To address this dearth in the literature, this study chose Malaysian's employees who work for restaurants. The purpose of this research was to examine the impact of diversity on teamwork performance at a dimensional level from the perspectives of Malaysian's employees in the hospitality industry. This study developed a conceptual framework that represents the relationship between cultural value diversity and multicultural teamwork performance at a dimensional level.

\section{Cultural Value Diversity}

Culture encompasses a whole set of beliefs, traditions, values, and expectations that characterize a particular group of people that identifies the uniqueness of the social unit (Leavitt \& Bahrami, 1988). It is a way of life where a group of people inherited from one generation to the next (Barnouw, 1963). Cultural values in the workplace then emerged and were described as cultural differences that can influence employee's perception of work environment (Hofstede, 1991). Cultural diversity is defined as a variety deposit of knowledge, information, experience, beliefs, values, attitudes, meanings, hierarchies, race, religion, notions of time, verbal and non-verbal behaviour acquired by a group of population through individual or teams (Hofstede, 1997). In other words, cultural value diversity refers to the understanding of different cultural characters among members in a team (Kirkman \& Shapiro, 2005).

Hofstede (1991) introduced Cultural Dimensions Theory to discuss how a society's culture influences the values of its members and their behavior. The theory describes cultural values in four dimensions: individualism-collectivism, uncertainty avoidance, power distance, and masculinity-femininity. Referring to Hofstede's theory, Kirkman and Shapiro (2005) proposed four dimensions of cultural value diversity, namely, collectivism, determinism, power distance, and doing orientation which were more related to the workplace study setting. Dekker, Rutte, and den Berg (2008) applied the four dimensions to compare members' cultural values in virtual teams from different countries (i.e. United States, India, and Belgium) and measure whether they perceived the same interaction behaviors to be critical.

Collectivism refers to the extent of someone values an individual as interdependent with the group that they belong (Markus \& Kitayama, 1994). Collectivist would appreciate the relationships with team members. In contrast to people who believe emphasizing the individual feel, they would be most comfortable with voluntary and informal teams. 
Collectivistic orientation offers many potential implications towards team and service industry. For instance, Wagner (1995) observed that collectivistic team values could increase cooperation in an organization. That is, collectivist will share characteristics and identify more strongly with their work teams (Chatman, Polzer, Barsade, \& Neale, 1998).

On the other hand, individuals from dominant "deterministic" believe that external forces govern their actions. Individuals from non-deterministic cultures, however, believe that they have very little control over their environment rather than control their own destiny (Adler, 1997). When individuals engage in a performance-related task, they typically take actions to reach certain standards. These actions may include directly altering their behavior in order to more closely match a standard and require the individuals changed their environment in some way (Tsui \& Ashford, 1994). This attitude has been widely practiced in the United States, Canada, and Australia (Kirkman \& Shapiro, 1997).

Doing-oriented people emphasize work accomplishments to achieve goals and maximize work (Adler, 1997). It is noted that people who are doing-oriented work longer hours in order to earn more money. As opposed to this trait, being-oriented employees work only as much as needed to be able to live, and minimize work (Adler, 1997). A comparison study has been conducted between cultures with a dominant being-orientation (i.e. Mexico) and a country with a dominant doing-orientation (i.e. United States) found Mexican employees spent fewer hours at work and more time with family after received pay raises and bonuses, however, similar pay raises often prompted employees in the United States to work longer hours in order to earn more money.

Lastly, power distance is defined as the acceptance level of community imbalance among society (Hofstede, 1980). It is reported that the degree of inequality varies in different cultures and nationalities. Furthermore, in societies with low power distance, people strive to equlaize the distribution of power and demand justification for inequalities of power. This value orientation model has served as a tool to understand cultures and help organizations to minimize conflicts among employees within diverse cultures.

\section{Multicultural Teamwork Performance}

In the last decade, multinational or multicultural teamwork (MCT) has emerged, which consists of members from different countries or cultures. MCT can be located in a single country or dispersed across many different countries. Barrick, Stewart, Neubert and Mount (1998) defined team perfomance as team outcomes associated with productivity, as well as to the capability of team members to continue working cooperatively. Diverse work teams bring high value to organizations. Respecting individual differences will benefit the workplace by creating a competitive edge and increasing work productivity (Green, López, Wysocki, \& Kepner, 2009). Moreover, team output is depends on individual contributions, which explained by Hackman (1990) that cooperation as the key to developing a team with the long-term capability to work interdependently, which foster cooperation and trust.

Scholars have paid attention on how cultural diversity on team member variables (i.e. collectivism, determinism, \& doing orientation) can influence teamwork performance (Bell, 2007; Cheng, Chua, Morris, \& Lee, 2012; King, Hebl, \& Beal, 2009). For instance, Cheng et al (2012) examined the effectiveness of multicultural teams by observing teams' performance, problem-solving skills, and contribution within a diversified team setting. The study argued that moderate variance among team members is essential to effective team performance. On the other hand, King, Hebl, and Beal (2009) revealed that conflict among multicultural team could impact cooperation among team members. They suggest that dissimilarity among group members are more likely to experience conflicts; thus have negative outcomes on cooperation among teams. 


\section{Diversity in Malaysia}

In Malaysia, the influx of the immigrant population has resulted in an increased number of MCT in many organizations. The term multiracial can no longer portray the belief of majoring races include Malay, Chinese, and Indian as quite numbers of 'additional-colors' flooding here in Malaysia. The impact of these phenomena had nevertheless solved workforce problems especially labor shortage. Due to this notion, Malaysia's industries depend heavily on foreign workers thus as a result imported a large number of foreign workers. They mainly work in the service sectors including restaurants, hotels and domestic maids (Hamid, 2009). In order to deal with labor scarcity, most restaurants in Malaysia employed both local and foreign workers to accommodate each business.

Foreign workers with different cultures, beliefs, nationality and other demographic diversity led to multicultural teamwork (Chatman et al., 1998). This situation steered to a multi-nationality workforce which contribute to a noteworthy impact on the hospitality industry. The growing numbers of immigrants in Malaysia have resulted in the rising of diverse culture, value, and language. The combination and dissimilarities in different languages such as Malay language, Nepali language, in Tagalog and Malayo-Polynesian language can result in influencing the multicultural teamwork performance and contribute to an ineffective team process within an organization (Mohamad, 2003).

\section{A Conceptual Framework}

A proposed model in the current study was developed to examine the impact of cultural value diversity on work performance (see Figure 1). This holistic framework represents the impact of cultural value on teamwork performance. Cultural value diversity was evaluated by three dimensions of collectivism, determinism, and orientation, which represent relationships among employees. Power distance, a cultural diverse dimension was excluded in this study because it represents a relationship between a leader (employer) and a follower (employee). Multicultural teamwork performance was measured by two aspects, namely productivity and cooperation. Therefore, the following hypotheses are proposed:

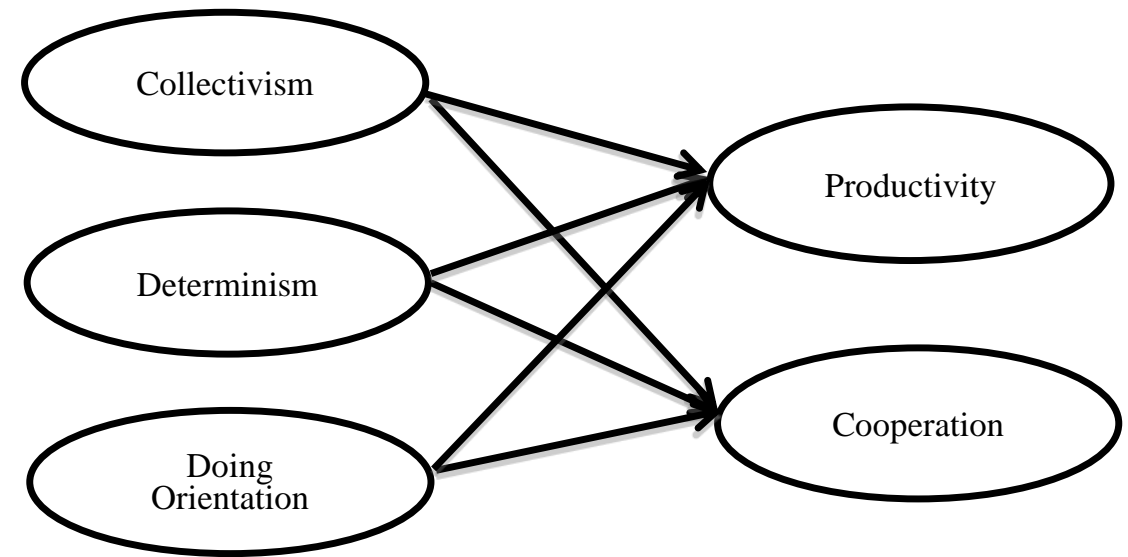

Figure 1. Proposed model

H1: Cultural value diversity has a significant impact on multicultural teamwork performance.

H1.1: Collectivism diversity has a significant impact on productivity.

H1.2: Collectivism diversity has a significant impact on cooperation.

H1.3: Determinism diversity has a significant impact on productivity. 
H1.4: Determinism diversity has a significant impact on cooperation.

H1.5: Orientation performance has a significant impact on productivity.

H1.6: Orientation performance has a significant impact on cooperation.

\section{RESEARCH METHOD \\ Instruments}

The survey questionnaire consisted of three sections. The first section included a total of 12 items to measure the cultural value diversity in the three perspectives of collectivism, determinism, and orientation performance (Kirkman \& Shapiro, 2005, Maznevski, et al., 2002). The second section consisted of eight items to evaluate work performance in the two dimensions of productivity and cooperation (Kirkman \& Shapiro, 2005; Campion, Medsker \& Higgs, 1993). This study used a 5-point Likert scale ranging from 1 (strongly disagree) to 5 (strongly agree). The final section included demographic information of respondents.

\section{Pilot Study}

In order to ensure that the wording of the questionnaire was clear, a pilot test was performed on 30 dining and cafeteria workers at a university in Malaysia. Some items were modified to enhance clarity of the questions. All measurements were above the cutoff of 0.70 in reliability, which indicated good internal consistency (Nunnally, 1978).

\section{Sampling and Data Collection}

Employees who worked for casual ethnic restaurants with a mixture of foreign and local workers have been chosen as the study sample. A self-administered questionnaire was distributed to the employees in 24 casual ethnic restaurants in the district of Petaling in Malaysia. The selected restaurants were identified as having a balanced number of local and foreign workers. The survey was open for two months to 240 respondents and 150 responses were returned, corresponding to a response rate of $62.5 \%$.

\section{Data Analyses}

The IBM SPSS Statistics 23 and Mplus structural equation modeling (SEM) were employed to test the hypothesized relationships. Mplus is an effective analytical tool to examine a broad array of models based on a wide choice of estimators for analyses of continuous, categorical, dichotomous, and censored data (Byrne, 2012). In particular, Mplus is an appropriate approach to treat the data of a small sample size (Muthen \& Muthen, 2002). The two-step analysis was conducted. The first step involved a confirmatory factor analysis (CFA) to test how well all the measured variables represent the number of constructs. The second step involved a structural equation modeling (SEM) analysis to estimate the causal relationship among cultural value diversity and teamwork performance (Anderson \& Gerbing, 1988).

\section{RESULTS AND DISCUSSION}

Table 1 shows the profile of the respondents. Of the participants in the study, 52 percent of the participants were male and 48 percent were female, most are between 16 and 30 years old (88 percent). More than half of the participants have foreign nationality (64 percent). The majority of the respondents completed tertiary education (54 percent) with a large majority has below 3 years of organizational ( 86.7 percent) and job tenure (68.7 percent). 
Table 1. Respondents' profile

\begin{tabular}{|c|c|c|}
\hline & Frequency (N) & Percentage (\%) \\
\hline \multicolumn{3}{|l|}{ Gender } \\
\hline Male & 78 & 52.0 \\
\hline Female & 72 & 48.0 \\
\hline \multicolumn{3}{|l|}{ Age } \\
\hline $16-20$ years old & 16 & 10.7 \\
\hline 21-25 years old & 69 & 46.0 \\
\hline $26-30$ years old & 48 & 32.0 \\
\hline $31-35$ years old & 9 & 6.0 \\
\hline $36-40$ years old & 8 & 5.3 \\
\hline \multicolumn{3}{|l|}{ Nationality } \\
\hline Bangladesh & 19 & 12.7 \\
\hline Philippines & 21 & 14.0 \\
\hline Indonesia & 22 & 14.7 \\
\hline Malaysia & 54 & 36.0 \\
\hline Nepal & 13 & 8.7 \\
\hline Myanmar & 12 & 8.0 \\
\hline Thailand & 9 & 6.0 \\
\hline \multicolumn{3}{|l|}{ Education Level } \\
\hline Primary school & 17 & 11.3 \\
\hline Secondary/High school & 52 & 34.7 \\
\hline Certificate & 29 & 19.3 \\
\hline Diploma & 40 & 26.7 \\
\hline Bachelor/Degree & 12 & 8.0 \\
\hline \multicolumn{3}{|l|}{ Organizational Tenure } \\
\hline$<1$ year & 66 & 44.0 \\
\hline $1-3$ years & 64 & 42.7 \\
\hline $4-6$ years & 12 & 8.0 \\
\hline 7-9 years & 8 & 5.3 \\
\hline \multicolumn{3}{|l|}{ Job Tenure } \\
\hline$<1$ year & 36 & 24.0 \\
\hline $1-3$ years & 67 & 44.7 \\
\hline 4-6 years & 27 & 18.0 \\
\hline $7-9$ years & 18 & 12.0 \\
\hline$>10$ years & 2 & 1.3 \\
\hline
\end{tabular}




\section{Measurement Model}

In order to examine the statistical significance of the weights of sub-constructs and the path coefficient, a bootstrapping procedure with 300 iterations was performed (Chin, Peterson, \& Brown, 2008). The CFA results revealed that the overall fit of the measurement model was satisfactory $\left(\chi^{2}(80)=143.158, p<.001\right.$, RMSEA $=.073, \mathrm{CFI}=.942$, TLI $\left.=.924\right)$.

\section{Reliability and Validity}

Cronbach's alpha values of each construct are higher than .7, which shows good reliability (Hair, Black, Babin, \& Anderson, 2010). In addition, composite reliability (CR), average variance extracted (AVE), and factor loadings were examined for the reliability and validity of the measurements (see Table 2). The CR values for each variable range from .958 to .976, which exceeded the recommended threshold value of .7 (Hair et al., 1998). The AVE values range between .562 and .717, which is greater than cutoff value of .5 (Bagozzi \& Yi, 1988). Finally, all factor loadings were significant at the .001 levels. Overall, the findings suggested a satisfactory reliability and convergent validity (Anderson \& Gerbing, 1988).

Table 2. Measure results

\begin{tabular}{|c|c|c|c|c|c|c|}
\hline Latent variables and corresponding items & Mean & SD & $\begin{array}{c}\text { Item } \\
\text { loading }\end{array}$ & $\begin{array}{c}\text { Cronbach } \\
\text { alpha }\end{array}$ & $\begin{array}{l}\text { Composite } \\
\text { Reliability }\end{array}$ & AVE \\
\hline Collectivism & & & & 0.793 & 0.958 & 0.562 \\
\hline $\begin{array}{l}\text { C1. Needs of team should take priority over } \\
\text { personal needs }\end{array}$ & 3.852 & 0.617 & 0.755 & & & \\
\hline C2. Problem solving by groups gives better results & 3.848 & 0.586 & 0.737 & & & \\
\hline C3. Teamwork is better than working alone & 4.062 & 0.627 & 0.757 & & & \\
\hline Determinism & & & & 0.832 & 0.965 & 0.639 \\
\hline D1. Team believes able to overcome obstacles & 3.647 & 0.764 & 0.691 & & & \\
\hline D2. Team believes we cannot control forces & 3.445 & 0.766 & 0.908 & & & \\
\hline D3. Team not trying to change basic direction & 3.335 & 0.843 & 0.784 & & & \\
\hline Orientation performance & & & & 0.795 & 0.958 & 0.573 \\
\hline 01. It is important to get work done before relaxing & 3.900 & 0.627 & 0.847 & & & \\
\hline 02. Live to work, not work to live & 3.971 & 0.683 & 0.735 & & & \\
\hline 03. Doing nothing is wasting time & 3.916 & 0.762 & 0.679 & & & \\
\hline Team Productivity & & & & 0.882 & 0.976 & 0.717 \\
\hline TP1. Team completes tasks and meets goals & 3.920 & 0.617 & 0.773 & & & \\
\hline TP2. Team produces high quality products/services & 3.912 & 0.651 & 0.829 & & & \\
\hline TP3. Team sets own production standards & 3.931 & 0.650 & 0.931 & & & \\
\hline Team Cooperation & & & & 0.813 & 0.965 & 0.611 \\
\hline TC1. Team members cooperate to get work done & 3.811 & 0.687 & 0.836 & & & \\
\hline TC2. Team members willing to share information & 3.838 & 0.696 & 0.820 & & & \\
\hline TC3. Team members contribute equally to the work & 3.900 & 0.724 & 0.680 & & & \\
\hline
\end{tabular}

\section{Structural Equational Model Analysis}

The goodness-of-fit statistics for the structural model were satisfactory, $\chi^{2}(80)=143.158$, $p<.001$, RMSEA $=.073$, CFI $=.942$, TLI $=.924$ (see Figure 2 ). Collectivism diversity had a significant impact on both productivity $(\beta=.476, p<.01)$ and cooperation $(\beta=.363, p<.01)$. However, determinism diversity was found to have no significant impact on both productivity $(\beta=-.034, p=.708)$ and cooperation $(\beta=-.019, p=.842)$. Kirkman and Shapiro (2005) also found small significant findings on determinism comparing employees in the Philippines and the U.S. which mainly because of the employees' attitude. Lastly, doing orientation was found to have a significant impact on cooperation $(\beta=.281, p<.05)$ but not on productivity $(\beta=.125, p=.288)$. 


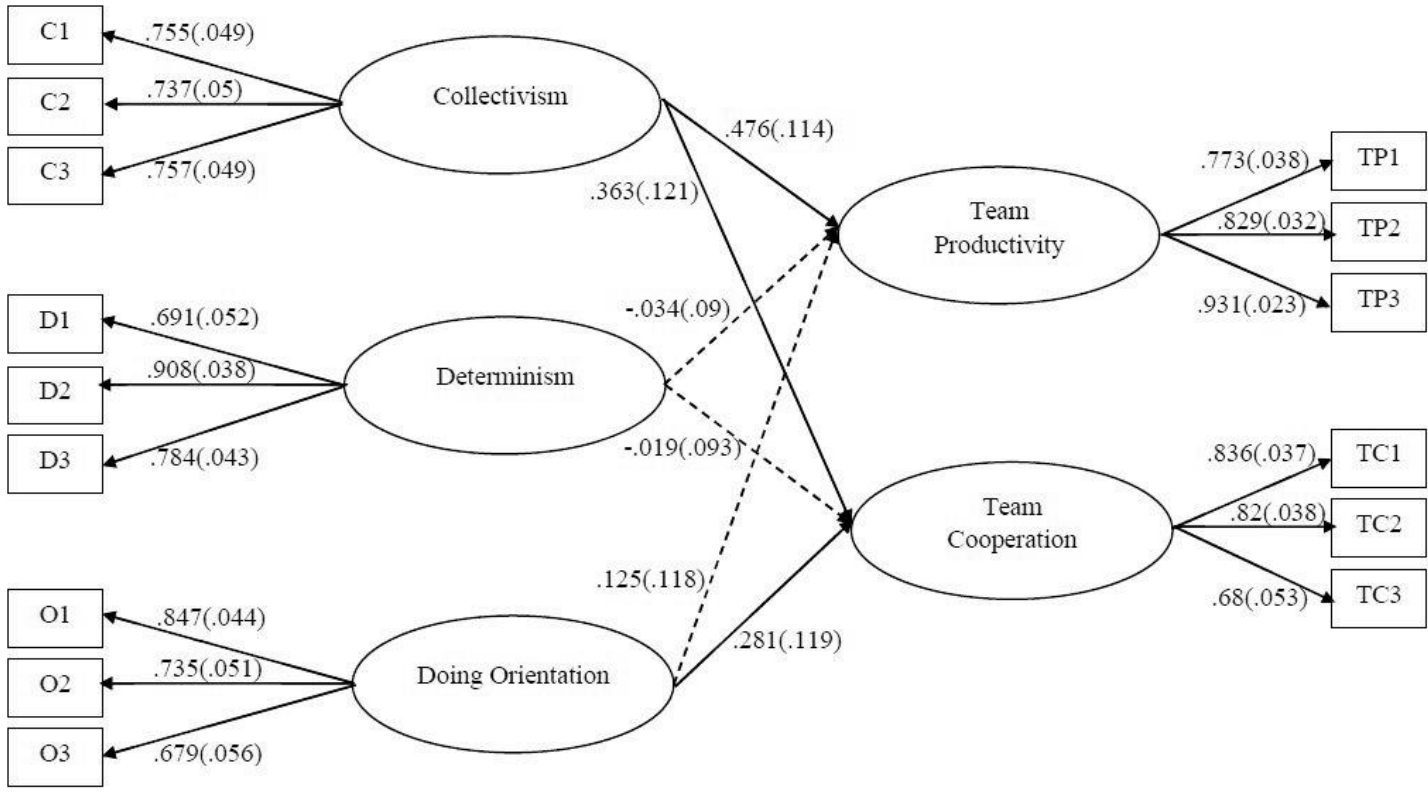

Figure 2. Structural Model

This study results showed the impact of cultural value diversity on multicultural teamwork performance given the multicultural environment of Malaysia, consisting of local and foreign workers, particularly, in the restaurant context. The research results showed the impact of cultural value diversity towards multicultural teamwork performance. First, collectivism diversity had a significant influence on both team productivity and cooperation. This implies that restaurant employees from different nationalities and collectivism cultures could efficiently work together as a productive team. Although they have difficulties understanding language and adapting to a new culture, employees believed that if they worked in a group, most problems could be overcome. This experimental result has been supported by a previous study that collectivism value could ameliorate team performance (Noordin \& Jusoff, 2010).

Secondly, while determinism has received little empirical attention in the literature (Earley, 1997), the results revealed that determinism diversity had no impact on team performance - both productivity and cooperation. This implies that determinism trait may be not as an important factor as other variables (collectivism and doing orientation) in influencing teamwork productivity and cooperation.

Lastly, doing orientation was found to have a significant, positive effect on team performance, particularly, cooperation. This indicates that employees who are oriented to their jobs are more likely to cooperate, help, and support each other. This finding is consistent with previous studies found that doing oriented persons could increase performance among teamwork (Adler, 1997; Green, López, Wysocki, \& Kepner, 2009).

\section{Theoretical Contribution}

Numerous studies have examined cultural value diversity (Kirkman \& Shapiro, 2005; Tröster, Mehra, \& Knippenberg, 2014), however, this current study offer a new methodological perspective from subdimensional constructs. Specifically, cultural value diversity includes the subdimensions of collectivism, determinism, and doing-orientation. Teamwork performance includes two subdimensions, team productivity and team 
cooperation. Therefore, the model of this study includes five subdimensions in its dimensions of cultural value diversity and teamwork performance.

By considering each cultural value diversity and teamwork performance as a subdimensional construct, the findings offer novel addition to the literature. The discoveries exhibit that each dimension of cultural value diversity (i.e. collectivism, determinism, and doing orientation) had different relationship forms as the illustrated different paths to the two dimensions of teamwork performance (i.e. productivity and cooperation). This new finding thus offers a distinctive methodological approach to identify cultural diversity and performance relationships in a more specific way and holistic insights. Therefore, this study makes a theoretical contribution on deepening our understandings of the detailed relationships between the two constructs thus suggests that future research at the subdimensional level would contribute to more precise association values among constructs.

In addition, given the fact that there are insufficient studies related to cultural value diversity and teamwork performance in the restaurant industry, this study broadens the literature on the relationship among multicultural restaurant employees, particularly in Malaysia. For instance, the findings reveal that although the restaurant employees originally came from different countries, they have the similar values of collectivism and determinism that unites them thus increasing team productivity and performance of the restaurant.

Although there are numbers of studies investigating cultural value diversity and team performance, however, the impacts of each diversity towards team performance are still being debated (Pelled, Eisenhardt, \& Xin, 1999). Hence, the findings may provide a potential opportunity to explain why previous studies have shown inconsistent findings on diversity's impact towards teamwork performance (Earley \& Mosakowski, 2000; Troster, Mehra, \& Knippenberg, 2014).

\section{CONCLUSION}

Organizations are continually becoming more diverse as the workforce expands. The workforce is preparing for an individual to work together with others who have different gender, race, religion, physical disabilities, and age. By providing empirical evidence of the current situation of workforce diversity in the restaurant industry in Malaysia, this study will help restaurant managers to deal with diversity challenges in organizations. It is crucial for the restaurant management to prepare managers with the skills and techniques to help diverse teams with potential obstacles in the workplace.

Through findings from this study, strategic management could be implemented within the organization by focusing on the hiring process. As collectivism and doing orientation were found to increase performance, an organization should consider recruiting individuals with these particular attributes. Managers have to test the candidates and ask some cultural values-related questions during the interview. From there, the managers could hire collectivists and doing-oriented employees thus increase team performance in the restaurant.

For business managers particularly, this paper shows that the only employees with two attitudes are worth to hire (i.e. collectivism and doing-oriented), which will strongly direct companies' future performances. Due to the industrial challenge for companies to work in adaptive and dynamic ways, we find the discussion of cultural value diversity and teamwork performance as worth developing further. 


\section{REFERENCES}

Ab-Latif, Z. (2019). The effect of collectivism diversity towards multicultural teamwork performance among restaurant employees.Journal of Vocational Education Studies, 2(2), 91-100.

Adler, N. J. (1997). International Dimensions of Organizational Behavior (3 ${ }^{\text {rd }}$ ED). Cincinnati, $\mathrm{OH}$ : South-Western College Publishing.

Alesina, A., \& La Ferrara, E. (2005). Ethnic diversity and economic performance. Journal of Economic Literature, 43(3), 762-800.

Anderson, J. C., \& Gerbing, D. W. (1988). Structural equation modeling in practice: A review and recommended two-step approach. Psychological bulletin, 103(3), 411.

Bagozzi, R. P., \& Yi, Y. (1988). On the evaluation of structural equation models. Journal of the Academy of Marketing Science, 16(1), 74-94.

Barak, M. E. M. (2013). Managing diversity: Toward a globally inclusive workplace. Sage Publications.

Barnouw, V. (1963). Culture and Personality. Homewood, Il: Dorsey Press.

Barrick, M. R., Stewart, G. L., Neubert, M. J., \& Mount, M. K. (1998). Relating member ability and personality to work-team processes and team effectiveness. Journal of Applied Psychology, 83(3), 377.

Bell, S. T. (2007). Deep-level composition variables as predictors of team performance: a meta-analysis. Journal of Applied Psychology, 92(3), 595.

Bhadury, J., Mighty, E. J., \& Damar, H. (2000). Maximizing workforce diversity in project teams: A network flow approach. Omega, 28, 143-153.

Byrne, B. M. (2012). Structural equation modeling with Mplus: Basic concepts, applications, and programming. New York: Taylor \& Francis Group.

Campion, M. A., Medsker, G. J., \& Higgs, A. C. (1993). Relations between work group characteristics and effectiveness: Implications for designing effective work groups. Personnel Psychology, 46, 823-850.

Chatman, J. A., Polzer, J. T., Barsade, S. G., \& Neale, M. A. (1998). Being different yet feeling similar: The influence of demographic composition and oganizational culture on work processes and outcomes. Administrative Science Quarterly, 43, 749-780.

Cheng, Chi-Ying, Chua, R. Y. J., Morris, M. W., \& Lee, L. (2012). Finding the right mix: How the composition of self-managing multicultural teams' cultural value orientation influences performance over time. Journal of Organizational Behavior, 33, 389-411. doi:10.1002/job.1777

Chin, W. W., Peterson, R. A., \& Brown, S. P. (2008). Structural equation modeling in marketing: Some practical reminders. Journal of Marketing Theory and Practice, 16(4), 287-298.

Dekker, D. M., Rutte, C. G., \& Van der Berg, P. T. (2008). Cultural differences in the perception of critical interaction behaviors in global virtual teams. International Journal of Intercultural Relations, 32(5), 441-452.

Dienes, D., \& Velte, P. (2016). The impact of supervisory board composition on CSR reporting. Evidence from the German two-tier system. Sustainability, 8(1), 1- 20. https://doi.org/10.3390/su8010063

Earley, P. C. (1997). Face, harmony, and social structure: An analysis of organizational behavior across cultures. Oxford University Press on Demand.

Earley, C. P., \& Mosakowski, E. (2000). Creating hybrid team cultures: An empirical test of transnational team functioning. Academy of Management Journal, 43(1), 26-49.

Eze, F., Okonkwo, O. M. L., Oluchi, M. L., \& Igwebuike, E. C. (2019). Effect of workforce diversity on the competitiveness of Nigerian Bottling Company South East, Nigeria. 
International Academy Journal of Management, Marketing and Entrepreneurial Studies, 7(1), 8 - 24.

Gallagher, S. (2001). The practice of mind. Theory, simulation or primary interaction?. Journal of Consciousness Studies, 8(5-6), 83-108.

Green, K. A., López, M., Wysocki, A., \& Kepner, K. (2012). Telecommuting as a true workplace alternative. University of Florida.

Hackman, J. R. (1990). Groups that work and those that don't (No. E10 H123). Jossey-Bass.

Hair, J. F., Anderson, R. E., Babin, B. J., \& Black, W. C. (2010). Multivariate data analysis: A global perspective (Vol. 7). Upper Saddle River, NJ: Pearson.

Hamid, B. A. (2009). The identity construction of women/maids in domestic help for hire discourse in selected Malaysian newspapers. European Journal of Social Sciences, 9(1), 168-180.

Higgs, M. (1996). Overcoming the problems of cultural differences to establish success for international management teams. Team Performance Management: An International Journal, 2(1), 36-43.

Hofstede, G. (1980). Culture Consequences: International Differences in Work-Related Values. Beverly Hills, CA: Sage.

Hofstede, G. (1991). Cultures and organizations-software of the mind: Intercultural cooperation and its importance for survival. McGraw-Hill.

Hofstede, G. (1997). Organization culture. The IBM handbook of organizational behavior, 193-210.

Kahane, L., Longley, N., \& Simmons, R. (2013). The effects of coworker heterogeneity on firm-level output: assessing the impacts of cultural and language diversity in the National Hockey League. Review of Economics and Statistics, 95(1), 302-314.

King, E. B., Hebl, M. R., \& Beal, D. J. (2009). Conflict and cooperation in diverse workgroups. Journal of Social Issues, 65(2), 261-285.

Kirkman, B. L., \& Shapiro, D. L. (1997). The impact of cultural values on employee resistance to teams: Toward a model of globalized self-managing work team effectiveness. Academy of Management Review, 22(3), 730-757.

Kirkman, B. L., \& Shapiro, D. L. (2005). The impact of cultural value diversity on multicultural team performance. Academy of Management Journal, 18, 33-67.

Kluckhohn, F., \& Strodbeck, F. L. (1961). Variations in value orientations. Evanston, IL: Row, Peterson.

Lavaty, S., \& Kleiner, B. H. (2001). Managing and understanding the French employee. Management Research News, 24(3/4), 45-48.

Lazear, E. (1999). Culture and language. Journal of Political Economy, 107(6), 29-95.

Leavitt, H. J., \& Bahrami, H. (1988). Managerial Psychology. Chicago: The University of Chicago Press.

Mandrell, B, \& Kohler-Gray, S. (1990). Management development that values diversity. Personnel, 67, 41-47.

Markus, H. R., \& Kitayama, S. (1994). A collective fear of the collective: Implications for selves and theories of selves. Personality and Social Psychology Bulletin, 20(5), 568579.

Maznevski, M. L., Distefano, J. J., Gomez, C. B., Noorderhaven, N. G., \& Wu, P.-C. (2002). Cultural dimensions at the individual level of analysis: the cultural orientations framework. International Journal of Cross-Cultural Management, 2, 275-295.

Mohamad, N. (2003). Amalan keselamatan di tapak bina: Kajian kes projek perumahan di daerah Johor Bahru, kertas kerja, Published by Universiti Teknologi Malaysia.

Muthén, L. K., \& Muthén, B. O. (2002). How to use a Monte Carlo study to decide on sample size and determine power. Structural equation modeling, 9(4), 599-620. 
Noordin, F., \& Jusoff, K. (2010). Individualism-collectivism and job satisfaction between Malaysia and Australia. International Journal of Educational Management, 24(2), 159-174.

Nunnally, J. (1978). Psychometric methods. New York: McGraw Hill.

Pelled, L., Eisenhardt, K. M., \& Xin, K. R. (1999). Exploring the black box: an analysis of work group diversity, conflict and performance. Administrative Science Quarterly, 44, 128.

Testa, M. R. (2007). A deeper look at national culture and leadership in hospitality industry. Hospitality Management, 26, 468-484.

Tröster, C., Mehra, A., \& van Knippenberg, D. (2014). Structuring for team success: The interactive effects of network structure and cultural diversity on team potency and performance. Organizational Behavior and Human Decision Processes, 124(2), 245255.

Timmermans, B., Ostergaard, C. R., \& Kristinsson, K. (2011). Does a different view create something new? The effect of employee diversity on innovation. Research Policy, 8(54), 500-509.

Tsui, A. S., \& Ashford, S. J. (1994). Adaptive self-regulation: A process view of managerial effectiveness. Journal of Management, 20(1), 93-121.

Wagner III, J. A. (1995). Studies of individualism-collectivism: Effects on cooperation in groups. Academy of Management journal, 38(1), 152-173.

Webber, S. S., \& Donahue, L. M. (2001). Impact of highly and less job-related on work group cohesion and performance: A meta-analysis. Journal of Management, 27, 141-162.

Woon, L.P. \& Kahl, C. (2015). Employment empowerment through Human Resource Department in enriching employee satisfaction: The Hilton way in Malaysia. TEAM Journal of Hospitality and Tourism, 11(1), 21-37. 